\title{
Surveying the Damage: The Consequences of Alcohol Misuse among Students in Public Universities in Uasin Gishu County, Kenya
}

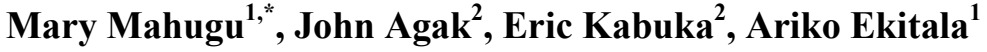 \\ ${ }^{1}$ Department of Student Affairs, Moi University, Kenya \\ ${ }^{2}$ Department of Educational Psychology, Maseno University, Kenya
}

Copyright $\bigcirc 2016$ by authors, all rights reserved. Authors agree that this article remains permanently open access under the terms of the Creative Commons Attribution License 4.0 International License

\begin{abstract}
Heavy and problematic alcohol use among college students has become a serious public health issue in Kenya. This alcohol consumption among the college student population is associated with numerous negative consequences such as assault, injury, risky sexual behavior, academic problems and property damage among others. This study sought to examine the prevalence of alcohol consumption among students in two public universities. The paper explored the drinking trends among students in the domains of normal use, harmful/hazardous drinking and alcohol dependency. The research design was a survey. The study area was University of Eldoret and Moi University in Uasin Gishu County. Four hundred students responded to the 10 item Alcohol Use Disorders Identification Test (Babor, Saunders, Higgins-Biddle and Monteiro,1992) [1] Data was analyzed using SPSS version 12. Descriptive statistics was adopted for frequencies and percentages. T-test was used to analyze gender differences in alcohol use. As this research documents, $30 \%$ of the respondents were taking an alcoholic drink at least once a month. Among the students using alcohol, $30 \%$ were engaging in hazardous alcohol use, while $49.5 \%$ were engaged in harmful alcohol use. A significant number of respondents displayed tendencies towards alcohol dependence (34\%). There is need for universities to formulate effective intervention measures to help curb high alcohol consumption among students.
\end{abstract}

Keywords University Student, Harmful/ Hazardous Alcohol Use, Binge Drinking

\section{Introduction}

Research findings show that 2 billion people worldwide consume alcoholic drinks, which can have immediate and long term consequences on health and social life. 76 million people are currently affected by alcohol use disorders, such as alcohol dependence and abuse. (GreenFacts, 2013) ${ }^{[2]}$ The world's highest alcohol consumption levels are found in the developed world, with the worldwide consumption in 2005 equal to 6.13 liters of pure alcohol consumed per person aged 15 years or older (WHO, 2011). ${ }^{[3]}$ According to the World Health Organization ${ }^{[3]}$ countries in the Americas, Europe and Western Pacific regions have relatively stable consumption levels while marked increases are seen in Africa and South-East Asia. Unrecorded alcohol consumption is estimated to be at least two-thirds of all alcohol consumption in the Indian subcontinent, about half of the consumption in Africa and about one-third in Eastern Europe and Latin America. Due to scanty research on drinking patterns in developing countries, the impact of the beverages that are made traditionally in villages or homes through fermentation of seeds, grains, fruits, vegetables and palm trees, is often not documented (WHO, 2014). ${ }^{[4]}$

More countries are reporting an increase in consumption and changes in drinking patterns in Africa. A significant characteristic pattern of alcohol consumption in the region involves episodic heavy drinking, defined as a drinking occasion that includes consumption of at least 60 grams of alcohol, that is, five or more standard drinks. (WHO Africa, 2007) ${ }^{[5]}$ Different alcohol consumption patterns create significant public health and safety problems in nearly all countries (WHO, 2011) ${ }^{[3]}$. The World Health Organization ${ }^{[3]}$ says about 2.5 million people die annually, and many more succumb to illness and injury, as a result of harmful alcohol use.

Alcohol is increasingly affecting younger generations and drinkers in both the developed and developing countries (Kenyan Officials, 2012). ${ }^{[6]}$ Kenya is one such country that is experiencing these negative repercussions from alcohol abuse. National Campaign against Drug Abuse (NACADA, $2012)^{[7]}$ notes that alcohol and drug abuse is highest among young Kenyan adults between the ages of 15 and 29. This 
age category is in adolescence and early adulthood. This heavy consumption of alcohol is associated with numerous negative consequences such as assault, injuries, risky sexual behavior, date rape, academic problems, vandalism, and property damage and police involvement among others.

Review of studies on alcohol use in Nigeria shows that there has been a rapid increase in alcohol availability and consumption in recent times with young adults in universities and colleges having a 77\% lifetime prevalence of alcohol use compared with between $51.5 \%$ and $56.0 \%$ found among youths in Nigerian cities. (Adewuya, Aloba, Mapayi, Ibigbami, Adewumi , 2007) ${ }^{[8]}$ Substance misuse is a growing problem in Ethiopia, as in many developing countries. Among some studies done in Ethiopian universities and colleges, a study in Axum University showed a lifetime prevalence of alcohol drinking 34.5\%, while a study in Addis Ababa University showed that 31.4\% of students ever drunk alcohol, (Tesfaye, Derese, \& Hambisa, 2014) ${ }^{[9]}$

Research carried out on drinking behavior of the youth in Kenya in particular, and Africa at large concentrates on urban youth and adolescents in high schools. Most of the studies focus on variables such as age of onset of drinking; lifetime frequency of drinking; drinking to intoxication; frequency, amount, and timing of current drinking. Among the few studies from universities and colleges in Kenya, Odek-Ogunde \& Pande-Leak (1999) ${ }^{[10]}$ reported high rates of substance use among students at a Kenyan private university, with rates as high as $84 \%$ for alcohol use. A study carried out in Eldoret, Uasin Gishu county reported a lifetime prevalence rate of alcohol use at $51.9 \%$, while $97.6 \%$ of alcohol users had consumed alcohol in the week prior to the study (Atwoli, Mungla, Ndung'u, Kinoti \& Ogot, 2011) ${ }^{[11]}$ None of these studies focused on investigating drinking patterns as a way of informing the detection of harmful or hazardous use among the respondents. The main objective of this study was to investigate the drinking trends of students in two public universities in Uasin Gishu County, in the domains of normal use, harmful/hazardous drinking and alcohol dependency.

\section{Methods}

Setting: The research was carried out in Moi University and the University of Eldoret in Uasin Gishu County. The two Universities are located in Eldoret, 310 kilometers Northwest of Nairobi, the Capital City of Kenya. Moi University students' population in all campuses currently stands at 28,851(Moi University, 2014) ${ }^{[12]}$ The University of Eldoret is one of the 22 public universities in Kenya which was a campus of Moi University until 2013 when it was awarded a Charter. The University has 25,000 students (The University of Eldoret, 2014) ${ }^{[13]}$ The population of the study was all male and female students in their $2^{\text {nd }}$ year of study in the two universities. There were an estimated 8000 students in their second year of study at the time of this study. Male students were approximately 4080 while the female students were 3920.

Sampling: Moi University has 10 campuses out of which five are located within Uasin Gishu County. For this study, only campuses within Uasin Gishu County were included. This was because the County was in the region recording the highest alcohol consumption levels in the country. The University of Eldoret has one campus in Uasin Gishu which was included in this study. A stratified sample of 400 students was identified to reflect representation of the two universities, and gender. The students sample size was arrived at by the use of Yamane formula at a 95\% confidence level (Yamane, 1967) ${ }^{[14]}$ Simple random sampling was used to identify individual participants from each strata using the students registration numbers.

Instruments: The students responded to the 10 item Alcohol Use Disorders Identification Test (Babor, Saunders, Higgins-Biddle and Monteiro, 1992) ${ }^{[1]}$ The AUDIT test has been developed from a six-country World Health Organization collaborative project as a screening instrument for hazardous and harmful alcohol consumption. Kenya was one of the six countries. It is a 10 -item questionnaire which covers the domains of normal use, harmful/hazardous drinking and alcohol dependency. Scores on the items are summed to a total score out of 40 , with a cut-off of $8+$ indicating harmful or hazardous drinking, and $13+$ to indicate a likelihood of alcohol dependence (Babor, et al, 1992 ${ }^{[1]}$ AUDIT provides a simple method of early detection of hazardous and harmful alcohol use in primary health care settings and is the first instrument of its type to be derived on the basis of a cross-national study. It has proven to be accurate in detecting alcohol dependence in university students (Fleming, Barry \& MacDonald, 1991) ${ }^{[15]}$ A test-retest reliability study indicated high reliability $(\mathrm{r}=.86)$ (Ivis et al., 2000) ${ }^{[16]}$ Its reliability and validity have therefore been established in research conducted in a variety of settings and in many different nations.

Procedure: The study was carried out in the period between August and October 2015. Administrative approval was sought and granted by Moi University and University of Eldoret. The AUDIT self-report questionnaire was administered to the respondents by the research assistants and collected the same day after being completed. No names or identifying information were indicated on the questionnaires, and all participants were assured of absolute confidentiality.

\section{Data storage analysis}

Data collected was entered into a Microsoft Excel database and analyzed using SPSS version 12. Descriptive statistics were used to compute means, standard deviations, frequencies and percentages. An alcohol use and abuse score was created by summing up all the scores obtained for the ten items in the AUDIT scale for each respondent. To determine the number of students in the two public universities who were abusing alcohol, the following AUDIT scale was used: 
Alcohol Score

Below Eight

$8.00-12.99$

$13.00-40$
Alcohol use/abuse level

Normal

Harmful/Hazardous drinking

Alcohol dependency reflected the view of Mugenda and Mugenda $(2003)^{[17]}$ who indicated that a response rate of $70 \%$ and over is very good as it gives a representative sample for meaningful generalization and minimizes errors.

\section{Results}

\section{Response rate}

Of the 400 questionnaires administered to students from the two public universities, $373(93.25 \%)$ were returned. The high return rate of the questionnaires is attributed to the simplicity of questions and the researchers' availability and commitment during data collection time. The response rate

\section{Biographic Details}

Descriptive results (Table 1) showed that the study sampled roughly the same number of male $(\mathrm{n}=186,50 \%)$ and female $(\mathrm{n}=187,50 \%)$ students. These proportions generally reflected the relative populations of male $(51 \%)$ and female $(49 \%)$ students in the two public universities.

Table 1. Bio-graphic information of respondents

\begin{tabular}{|c|c|c|c|}
\hline Panel A & Categories & Frequency & Percent \\
\hline Bio-graphic information & Male & 186 & 49.9 \\
Respondent's gender & Female & 187 & 50.1 \\
& Total & 373 & 100.0 \\
\hline Name of university & University of Eldoret & 217 & 51.8 \\
& Moi University & 373 & 100.0 \\
\hline Panel B & Total & Mean & Std. Dev. \\
\hline Bio-graphic information & Range & 21.92 years & 1.76 years \\
\hline
\end{tabular}

Key: Std. Dev = standard deviation; $\mathrm{n}=$ number of respondents

Source: Survey Data, 2015

Table 2. Respondents' alcohol use

\begin{tabular}{|c|c|c|c|c|c|}
\hline $\begin{array}{l}\text { 1. How often do you drink alcohol? } \\
\text { Sample responses }(n=335)\end{array}$ & $\begin{array}{c}\text { Never } \\
235(69.3)\end{array}$ & $\begin{array}{l}\text { Monthly or }< \\
72(21.2)\end{array}$ & $\begin{array}{l}2-4 \text { times/month } \\
19(5.6)\end{array}$ & $\begin{array}{l}2-3 \text { times/week } \\
5(1.5)\end{array}$ & $\begin{array}{c}4 \text { or }>/ \text { week } \\
8(2.4)\end{array}$ \\
\hline 2. How many alcoholic drinks in a day? & 1 or 2 & 3 or 4 & 5 or 6 & 7 to 9 & 10 or more \\
\hline Sample responses $(\mathrm{n}=104)$ & $77(74.0)$ & $10(9.6)$ & $8(7.7)$ & $4(3.8)$ & $5(4.8)$ \\
\hline 3. Times you have 6 or $>$ drinks? & Never & $<$ monthly & \multirow{2}{*}{$\begin{array}{l}\text { Monthly } \\
13(12.3)\end{array}$} & Weekly & Daily/almost daily \\
\hline Sample responses $(\mathrm{n}=106)$ & $61(57.5)$ & $19(17.9)$ & & $8(7.5)$ & $5(4.7)$ \\
\hline 4. Unable to stop drinking? & Never & $<$ monthly & Monthly & Weekly & Daily/almost daily \\
\hline Sample responses $(\mathrm{n}=103)$ & $69(67.0)$ & $10(9.7)$ & $11(10.7)$ & $6(5.8)$ & $7(6.8)$ \\
\hline 5. Unable to do expected things? & Never & $<$ monthly & Monthly & Weekly & Daily/almost daily \\
\hline Sample responses $(\mathrm{n}=101)$ & $68(67.3)$ & $17(16.8)$ & $10(9.9)$ & $1(1.0)$ & $5(5.0)$ \\
\hline 6. Drink in the morning & Never & $<$ monthly & Monthly & Weekly & Daily/almost daily \\
\hline Sample responses $(\mathrm{n}=102)$ & $67(65.7)$ & $14(13.7)$ & $10(9.8)$ & $6(5.9)$ & $5(4.9)$ \\
\hline 7. Have guilt after drinking & Never & $<$ monthly & Monthly & Weekly & Daily/almost daily \\
\hline Sample responses $(\mathrm{n}=101)$ & $51(50.5)$ & $26(25.7)$ & $14(13.9)$ & $3(3.0)$ & $7(6.9)$ \\
\hline $\begin{array}{l}\text { 8. Unable to remember what happened } \\
\text { at night due to alcohol }\end{array}$ & Never & $<$ monthly & Monthly & Weekly & Daily/almost daily \\
\hline Sample responses $(\mathrm{n}=102)$ & $69(67.6)$ & $17(16.7)$ & $7(6.9)$ & $2(2.0)$ & $7(6.9)$ \\
\hline $\begin{array}{l}\text { 9. Injured because of drinking? } \\
\text { Sample responses }(n=327)\end{array}$ & \multicolumn{2}{|c|}{$\begin{array}{l}\text { No } \\
66(81.3)\end{array}$} & \multicolumn{2}{|c|}{$\begin{array}{l}\text { Yes, but not in last year } \\
26(8.0)\end{array}$} & $\begin{array}{l}\text { during last year } \\
35(10.7)\end{array}$ \\
\hline $\begin{array}{l}\text { 10. Have people been concerned } \\
\text { because of your drinking? } \\
\text { Sample responses }(n=323)\end{array}$ & \multicolumn{2}{|c|}{ No } & \multicolumn{2}{|c|}{ Yes, but not in last year } & $\begin{array}{l}\text { during last year } \\
32(9.9)\end{array}$ \\
\hline
\end{tabular}

Key: numbers in parentheses are percentages; those without are the number of students who selected that answer; $\mathrm{n}=$ number of participants answering the question 


\section{Descriptive Results on Alcohol Use and Abuse}

The results showed that $70 \%$ of the students in the two universities never often take alcohol compared to about $30 \%$ who do. In other words, approximately three out of four students in the two universities never often take alcoholic drinks while one out of every four students consume alcohol in varying quantities. Most of those who consume were found to drink alcohol monthly or less $(21 \%)$ or $2-4$ times a month $(6 \%)$. Very few students drink alcohol 2-3 times in a week $(2 \%)$ or four or more times in a week $(2 \%)$. The results suggest that alcohol use amongst students in the two universities is not very extensive. These findings disagree with Human Resource Support Services (2012) ${ }^{[18]}$ a study carried out in Moi University which concluded that alcohol use among the students stands at $40 \%$.

Most students who were using alcohol (74\%) were found to take one or two alcoholic drinks on a typical drinking day, followed by those who took three or four drinks (18\%). Very few students were found to take five or six drinks $(8 \%)$, seven to nine drinks (4\%) or ten and more drinks $(5 \%)$. Slightly more than a half of the drinkers (58\%) never take six or more drinks on a single occasion relative to those who do. The latter group was dominated by students who imbibe six or more drinks in less than a month $(18 \%)$ or on a monthly basis $(12 \%)$. More students $(67 \%)$ were found to be able to stop drinking once they start compared to those who could not $(33 \%)$. Most students (67\%) felt that they could still be able to do what was normally expected despite drinking.

\section{1) Alcohol Use and Abuse}

Inter-item reliability as measured by the Cronbach's Alpha was found to be relatively high for the ten items in the scale $(0.734)$, which showed a high internal consistency. Thus, a respondent's alcohol use and abuse score was created by summing up all the scores obtained for the ten items in the AUDIT scale. These scores are presented in Table 4.4.

The alcohol use and abuse scale was computed for only 94 students who used alcohol. For the students who never used alcohol, they answered only three out of a possible ten questions. Consequently, an alcohol score could not be calculated for them because of the missing answers.

The alcohol score ranged from a minimum of one to a maximum of 31. The maximum possible score is 40 , implying that some student(s) could be abusing alcohol. The mean alcohol score was 8.87 , which was above the critical score of eight, indicating harmful or hazardous drinking amongst most students using alcohol. The standard deviation was quite large (6.91), which indicated wide disparities in alcohol usage amongst the students. This was supported by the wide range of alcohol scores (30), as given above. However, although the distribution of the variable showed skewdness (0.83) and kurtosis (0.34), the distributions did not depart too radically from the normal because the values of skew and kurtosis were within the benchmark of \pm 2 . This showed that the distribution of alcohol scores was almost symmetrical, implying that as many students abused alcohol as those who did not.

To determine the number of students in the two public universities who were abusing alcohol, the following scale was used:

$\begin{array}{ll}\text { Alcohol Score } & \text { Alcohol use/abuse level } \\ \text { Below Eight } & \text { Normal } \\ 8.00-12.99 & \text { Harmful/Hazardous drinking } \\ 13.00-40 & \text { Alcohol dependency }\end{array}$

Amongst the students who use alcohol in the universities, slightly more than half of them (52\%) exhibited harmful or hazardous drinking while $48 \%$ of them showed normal drinking (Table 4).

Table 3. Descriptive statistics for the respondents' alcohol use and abuse scores

\begin{tabular}{|c|c|c|c|c|c|c|c|c|c|}
\hline & $\mathrm{N}$ & Min. & Max. & Mean & Std. Dev. & \multicolumn{2}{|c|}{ Skew SE } & \multicolumn{2}{|c|}{ Kurtosis SE } \\
\hline $\begin{array}{c}\text { Alcohol } \\
\text { score }\end{array}$ & 94 & 1.00 & 31.00 & 8.8723 & 6.91614 & 0.828 & 0.249 & 0.338 & 0.493 \\
\hline
\end{tabular}

Key: $\mathrm{N}=$ number of respondents; Min. = minimum; Max. = maximum; Std. Dev. $=$ standard deviation; $\mathrm{SE}=$ standard error

Table 4. Frequencies of alcohol use/abuse among university students

\begin{tabular}{|c|c|c|c|c|c|}
\hline \multicolumn{2}{|c|}{} & \multicolumn{5}{|c|}{ Alcohol use/abuse level } & \\
\hline \multicolumn{2}{|c|}{} & Normal & $\begin{array}{c}\text { Harmful } \\
\text { drinking }\end{array}$ & $\begin{array}{c}\text { Alcohol } \\
\text { dependency }\end{array}$ & Total \\
\hline Students & $\begin{array}{c}\text { Frequency } \\
\%\end{array}$ & $\begin{array}{c}45 \\
\%\end{array}$ & $\begin{array}{c}20 \\
27.9\end{array}$ & 29 & 94 \\
& & 21.3 & 30.9 & 100.0 \\
\hline
\end{tabular}

Source: computed from survey data, 2015

Table 5. Means of alcohol scores according to gender

\begin{tabular}{|c|c|c|c|c|}
\hline & $\begin{array}{c}\text { Gender of } \\
\text { student }\end{array}$ & $\mathrm{N}$ & Mean & $\begin{array}{c}\text { Std. } \\
\text { Deviation }\end{array}$ \\
\hline \multirow{2}{*}{ Alcohol score } & Male & 64 & 9.00 & 6.935 \\
\cline { 2 - 5 } & Female & 30 & 8.60 & 6.986 \\
\hline
\end{tabular}

Of the students engaged in harmful drinking, many of them (31\%) showed high likelihoods of alcohol dependency. The findings were in agreement with Mahugu (2012) ${ }^{[19]}$ a study carried out among Moi University students which noted that there were students manifesting symptoms of alcohol dependence.

\section{Gender Differences in Alcohol Use and Abuse}

The results showed that amongst the teetolers, $56 \%$ $(n=157)$ of them were female while males constituted $44 \%$ $(\mathrm{n}=122)$. Amongst the students who drink, males made up $68 \%(n=64)$ of them while female constituted $32 \%(n=30)$. The results indicated that significantly more male than female students drink alcohol.

Amongst the students who take alcohol, the mean alcohol scores for male and female students were 9.00 and 8.60, respectively while their standard deviations were 6.94 and 6.99 , respectively. This indicated the mean alcohol score for male students was slightly more than that of the female 
students. However, the large standard deviations indicated there wide disparities in the alcohol scores among the students. The mean alcohol scores for both categories of students were just above the threshold of eight, suggesting that students who drink in college might be abusing alcohol.

Amongst the students who take alcohol, the mean alcohol scores for male and female students were 9.00 and 8.60, respectively while their standard deviations were 6.94 and 6.99 , respectively. This indicated the mean alcohol score for male students was slightly more than that of the female students. However, the large standard deviations indicated there wide disparities in the alcohol scores among the students. The mean alcohol scores for both categories of students were just above the threshold of eight, suggesting that students who drink in college might be abusing alcohol.

An Independent Samples t test was conducted to test whether the male and female alcohol score means were significantly different. The Independent samples t-test indicated that the alcohol score for male participants $(M=9.00, S D=6.94)$ was not significantly higher than that of female participants $(M=8.60, S D=6.99), t(92)=0.260$, $p=0.795,95 \%$ CI $[-2.655,3.455]$. Thus, alcohol abuse is likely to be similar amongst both male and female students. The finding agreed with another study (Atwoli, Mungla, Ndung'u, Kinoti and \& Ogot-, 2011) ${ }^{[11]}$ which notes that alcohol use and abuse among male and female students was not significantly different.

\section{Discussions and Conclusions}

The purpose of this study was to examine the prevalence of alcohol consumption among students in two public universities. The paper explored the drinking trends among students in the domains of normal use, harmful/hazardous drinking and alcohol dependency.

Findings of this study indicate that alcohol use prevalence among students was at $30 \%$. The findings agree with the WHO (2014) ${ }^{[4]}$ global status on alcohol which puts the number of abstainers in Kenya at $64.6 \%$. While prevalence for heavy episodic drinking in Kenya is at $1.4 \%$ (WHO, $2014)^{[4]} 39 \%$ of the respondents reported taking between 5 and 9 alcoholic drinks on a typical day when drinking. This translates to about 39 respondents or $11 \%$ of the entire study sample. The findings therefore indicate that college students engage in binge drinking more than the general population in Kenya.

According to the AUDIT results interpretation, about 30\% of students using alcohol were therefore engaging in hazardous ( risky) alcohol use. Hazardous drinking is a pattern of alcohol consumption that increases the risk of harmful consequences for the user or others (Babor, 1992) ${ }^{[14]}$ Hazardous drinking patterns are of public health significance despite the absence of any current disorder in the individual user. In this study, hazardous use involved drinking 5 or more drinks in a typical drinking episode, and engaging in such episodes frequently in a month.
The study findings also indicate that the respondents were engaging in harmful use which refers to alcohol consumption that result in consequences to physical and mental health. This was evidenced by $49.5 \%$ of the respondents using alcohol, who were unable to remember what happened the night before because they had been drinking during the last year, $33 \%$ who felt guilt or remorse after drinking, 33\% who needed a first drink in the morning to get them going. This translated to about 39 respondents or $10 \%$ of the entire study sample. This finding was significant since WHO (2014) ${ }^{[4]}$ puts the percentage of Kenyans engaging in harmful alcohol use at $1.9 \%$.

Babor et al $(1992)^{[1]}$ defines alcohol dependence as a cluster of behavioral, cognitive, and physiological phenomena that may develop after repeated alcohol use. These phenomena include a strong desire to consume alcohol, impaired control over its use, persistent drinking despite harmful consequences, a higher priority given to drinking than to other activities and obligations, increased alcohol tolerance, and a physical withdrawal reaction when alcohol use is discontinued. Of the students using alcohol in this study, about $34 \%$ displayed clear symptoms of alcohol dependence. This translates to about 34 respondents, or $9 \%$ of the entire study sample. According to WHO (2014) ${ }^{[4]}$ the percentage of Kenyans thought to be alcohol dependent is $1.4 \%$. Therefore the findings of this study are very significant since they point to a difference in prevalence rates among different social categories. The findings were also in agreement with Mahugu (2012) ${ }^{[19]}$ a study carried out among Moi University students which noted that there were students manifesting symptoms of alcohol dependence.

Study findings show that male students are likely to use alcohol more than their female counterparts. Among the students who used alcohol there are no significant differences in tendencies to engage in hazardous alcohol use among male and female students. The mean alcohol scores for both male and female students were just above the threshold of eight, suggesting that students of both genders who drink in college might be abusing alcohol.

This study concludes that hazardous and harmful alcohol use is a reality in our college campuses today leading to alcohol dependence among some of the students. With the rising cases of alcohol abuse and alcoholism, there is need for universities to formulate effective intervention measures to help curb high alcohol consumption among students. Interventions for harmful alcohol use prevention in college campuses lack efficacy data, creating a need for further research to understand the reasons why college students continue to use alcoholic drinks despite the consequences of heavy alcohol use.

\section{REFERENCES}

[1] Babor,T.F., Saunders, J.B., Higgins-Biddle,J.C., and Monteiro, M.G. (1992) The Alcohol Use Disorders Identification Test. Guidelines for Use in Primary Care. WHO. 
[2] GreenFacts (2013) Facts on Health and the envilonment. Retrieved from http://www.greenfacts.org/ Copyright (C) page $1 / 54$ retrieved on $14^{\text {th }}$ march 2013 .

[3] WHO (2011). Global Status Report on Alcohol and Health. Retrieved from http://www.who.int/substance_abuse/publica tions/global_alcohol_report/msbgsruprofiles.pdf

[4] WHO (2014) Global status report on alcohol and health. Retrieved from http://www.who.int/substance_abuse/publica tions/global_alcohol_report/en/

[5] WHO Africa (2007). Alcohol, gender and drinking problems: perspectives from low and middle income Countries. Department of Mental Health and Substance Abuse, Geneva. Retrieved from http://www.who.int/substance abuse/publica tions/alcohol_gender_drinking_problems.pdf

[6] Kenyan Officials (2012). Alcohol abuse is a National catastrophe. Nairobi: Act Press. Tuesday, 28 August 2012 20:56. Retrieved from http://www.voanews.com/content/ken ya_officials_say_alcohol_abuse_is_national_catastrophe/149 $70 \overline{7} 8 . \mathrm{html}$

[7] NACADA (2012) rapid situation assessment of the status of drug and substance abuse in Kenya. Retrieved from http://www.nacada.go.ke/documents-and-resources/category/ 9- policy-brief on 18/3/2013

[8] Adewuya, O., Aloba, O., Mapayi, B., Ibigbami, O., \& Adewumi , T. (2007). Alcohol Use Disorders among Nigerian University Students: Prevalence and Sociodemographic Correlates Nigerian Journal of Psychiatry Vol. 5. No. 1, 2007.

[9] Tesfaye, G., Derese, A.,and Hambisa, M. (2014). Substance Use and Associated Factors among University Students in Ethiopia: A Cross-Sectional Study Journal of Addiction Volume 2014, Article ID 969837, http://dx.doi.org/10.1155/ $2014 / 969837$
[10] Odek-Ogunde $\mathrm{M}^{1}$, Pande-Leak D. (1996). Prevalence of substance use among students in a Kenyan University: a preliminary report. East Afr Med J. 1999 Jun;76(6):301-6.

[11] Atwoli, 1., Mungla, P., Ndung'u, M., Kiende C Kinoti, K., \& Ogot, E. Prevalence of substance use among college students in Eldoret, western Kenya BMC Psychiatry 2011, 11:34 doi:10.1186/1471-244X-11-34.

[12] Moi University (2014). Records on students' enrollment. Admissions office

[13] University of Eldoret (2014). Records on students' enrollment. Admissions office

[14] Yamane,T., (1967). Statistics: An Introductory Analysis, 2nd Edition, New York: Harper and Row.

[15] Fleming, M., Barry, K. and MacDonald, R. (1991). The alcohol use disorders identification test (AUDIT) in a college sample. International Journal of the Addictions 26:1173-1185, 1991

[16] Ivis, F., Adlaf, E. \& Rehm, J.(2000). Incorporating the Audit into a general population telephone survey: a methodological experiment. Drug and alcohol Dependence 60: 97 - 104.

[17] Mugenda, O. M. \& Mugenda, A. G. (2003). Research methods: Quantitative and qualitative Approaches. Nairobi: African Centre for Technology Studies.

[18] Human Resource Support Services. (2012) Baseline Survey to Establish Prevalence of Alcohol and Drug Abuse in Moi University. Moi University.

[19] Mahugu, M., The treatment and Rehabilitation of alcoholics within the Moi University Counseling Unit: An outpatient Multimodal Approach. Report of the National Alcohol and Drug Abuse Conference held at the Kenya Institute of Administration, January25th - $27^{\text {th }} 2012 . c 2013$ 